\title{
Vocabulary Memorizing Strategies by Chinese University Students
}

\author{
Wei-dong YANG (Corresponding author) \\ School of Foreign Languages, China University of Petroleum (Beijing) \\ 18 Fuxue Road, Changping District, Beijing 102249, China \\ Tel: 86-10-8973-3282Ｅ-mail: clarkdream@sina.com \\ Wei-ping DAI \\ School of Foreign Languages, China University of Petroleum (Beijing) \\ 18 Fuxue Road, Changping District, Beijing 102249, China \\ Tel: 86-10-8973-3282Ｅ-mail: dwping@cup.edu.cn
}

Received: September 19, 2011 Accepted: September 26, 2011 Published: February 1, 2012

doi:10.5539/ies.v5n1p208

URL: http://dx.doi.org/10.5539/ies.v5n1p208

\begin{abstract}
The findings of the study indicate that students prefer to engage in the vocabulary learning strategies that would be most appealing to them and that would entail less manipulation of the language. Of the four vocabulary memorizing strategies cited in the study (rote repetition, structural associations, semantic strategies, and mnemonic keyword techniques), students apparently tended to favor the second and the third ones, though rote repetition remains appealing to some of them. Mnemonic devices such as keyword method were rather unpopular to most of the students because they would involve the learners in more active performance of the target language.
\end{abstract}

KeyWords: Vocabulary, Memorizing strategies, Chinese university students

\section{Introduction}

A questionnaire is developed primarily on the basis of a general review of the relevant literature. It is designed to collect information about how the Chinese university students learn and memorize English vocabulary. The questionnaire was administered by the authors to 68 students (32 English majors and 36 non-English majors) at China University of Petroleum. It aims at getting their general responses to different questions on vocabulary learning and vocabulary memory strategies they prefer to use. The present paper summarizes the primary findings obtained from the study and briefly considers its implications for vocabulary learning for Chinese university students of English. The findings of the study indicate that students prefer to engage in the vocabulary learning strategies that would be most appealing to them and that would entail less manipulation of the language.

\section{Vocabulary Memorizing Strategies}

Vocabulary is by far the most sizable and unmanageable component in the learning of any language, whether foreign or one' mother tongue. No language acquisition can take place without the acquisition of lexis. As far as any of the world's major languages are concerned, every other aspect of language learning is dwarfed by the proliferation of different meanings in their tens of thousands, and the seemingly infinite shifts in meaning brought about by contextual variables. Language learners sometimes, if not often, feel that they cannot remember words that they attempt to learn. Such words are probably not committed to memory effectively, and not stored in such a way they may be easily retrievable when necessary. In order for learners to go about deepening their receptive or productive mastery of vocabulary items, they must first remember the words well enough to recognize them.

A considerable amount of research has taken place since the late 1970s concerning vocabulary memorizing strategies. Among the earliest studies that focused on memory strategy for vocabulary are those by Cohen and Aphek whose main interest was use of association. In one study Cohen and Aphek (1980) found that making associations and keeping using them were helpful to recall it. In another study Cohen and Aphek (1981) found that more successful associations would be the ones in which two items were closer in sound or meaning, or which had an emotional impact on the leaner.

In a study designed to identify the range, type, and frequency of learning strategy used by beginning and intermediate level of ESL students to improve second language learning and retention, O'Malley et. al (1985) found 
that strategies that entailed less active manipulation of the language task, e.g. repetition, note-taking, were most frequently employed than those that entailed active manipulation of learning materials, e.g. keyword techniques, grouping, contextualization. Their findings were consistent with those of Cohen and Aphek (1981) in that types of rote learning were more often used than more complex strategies. Studies based on data obtained from students' interviews and self reports have also revealed that learners engage in the ways that entail less active manipulation of the language tasks in learning vocabulary in a second language (O'Malley \& Chamot 1990; Pickett 1978; Sanaoui 1995). For example, learners have reported memorizing lists of words, taking notes of new vocabulary items, repeating words, and reviewing previously learned words.

Oxford emphasizes the importance of associations in memory strategy for vocabulary since the specific memory strategies that Oxford (1990, cited in Nation 1990) mentions consolidate the connection between word form and meaning in memory. Oxford's specific memory strategies are:

1) grouping language material into meaningful units

2) associating new language information to concept already in memory

3) placing new words into a context, such as a meaningful sentence, conversation or story

4) using semantic mapping

5) using keywords with auditory and/or visual links

6) representing sounds in memory in such a way that they can be linked with a target language word in order to remember it better

7) using mechanical techniques, such as writing words on cards and moving cards from one stack to another when a new word is learned.

Rivers (1983) summarizes the vocabulary-memorizing strategies normally used by the language learners as follows :

1) Some make lists and memorize them.

2) Some read a great deal and mark with an asterisk, a word they do not understand each time they meet it, thus creating their own frequency counts.

3) Some note down words in a short context, repeatedly writing down the same words until their meaning and use are assimilated.

4) Some make associations with words that sound or look similar in their native language, even though the meaning may be different.

5) Some practice using new words as they talk to themselves in order to commit them to long-term memory.

6) Some read dictionaries.

Rivers points out that students should not be forced to learn in ways that they find unappealing or personally unsatisfying if the ultimate goal for each student of developing autonomous long-term learning strategies is to be achieved.

Based on the studies and reports cited above it can be reasonably concluded that association, as one of the most useful strategies for vocabulary learning is frequently used by language learners in their attempts to commit words to long-term memory. The findings and reports cited above also indicate that rote-repetition, as a traditional way of vocabulary-learning strategies, is still favored by many language learners, especially those at the initial and intermediate stages. Language learners always seek the way they find most helpful for expanding and maintaining their knowledge of the lexicon.

\section{The Study}

A questionnaire is developed primarily on the basis of a general review of the relevant literature (mainly Cohen 1987, 1990; Cohen \& Aphek 1981; Nation 1990; O’Malley et. al. 1985; Pickett 1978; Rivers 1983, and Sanaoui 1995). It is designed to collect information about how the Chinese university students learn and memorize English vocabulary. The questionnaire was administered by the authors to 68 students (32 English majors and 36 non-English majors) at China University of Petroleum . It aims at getting their general responses to different questions on vocabulary learning and vocabulary memory strategies they favor.

The first part of the questionnaire is concerned with Note-taking. Respondents are asked to answer the questions of how they keep notes of vocabulary, how they write down new vocabulary items and how they organize vocabulary notes. The second part copes with Rote learning. Respondents are required to give their answers to different forms 
of rote repetition. The third part is devoted to Associations. Association here refers to a mnemonic link to some element or elements that would be useful in remembering vocabulary items. It includes a link to meaning, sound and meaning together, structure, contextualization, mental image, letter(s) in the word, proper names, sign, and so forth. Respondents are asked to give their answers to the specific association in vocabulary memorization such as structural association, semantic association, and mnemonic association. The last part aims at getting their response on four ways of attempting to commit new vocabulary to memory. They are Rote-learning, Structure, Semantic Strategies, and Mnemonic Devices. In order to supplement the responses from fixed questions and rating scales, at the end of each unit there was a space in which students are free to write down whatever they thought or did relating to the topic.

The statements designed here do not derive from a unified theoretical framework but rather from descriptive accounts from several different sources, consequently there may be some internal inconsistency in the statements. Because most existing literature is primarily concerned with ESL learners, some points that seem to be related to vocabulary learning by Chinese learners of English are added to the questionnaire based on the authors' experience in teaching English to Chinese learners of English.

\section{Principal Findings and Implications of the Study}

\subsection{Principal findings}

1) In investigating the ways that students use to take notes, a rather unexpected finding is that most respondents held a low opinion of N1, N2, and N3. What they preferred to do instead is they liked to keep notes in the margins of textbook.

2) In terms of content of notes, most students favor Chinese translation equivalents. What was written down along with a vocabulary item of target language was most usually its translation equivalents.

3) Students' positive responses to N11 indicate that more than $2 / 3$ of them did memorize lists of words when they learnt vocabulary.

4) In their efforts to memorize words, most of students concentrated their attention on the to-be-remembered word itself. They tried to memorize a vocabulary item mainly by saying, writing or reading it repeatedly in a mechanical way.

5) From students' responses to N27 it can be seen very clearly that more than $2 / 3$ of students enjoyed learning words by means of structural association. Most of them did use roots and affixes in their efforts to commit vocabulary item to memory.

6) Many students did not associate English words to Chinese words in sound.

7) Most of students responded positively to such kinds of associations as those involved with structure, physical sensation, activity, situation, a particular event, and meaning group.

8) Most of the students tried to remember the item by checking it in a dictionary, which shows that dictionaries apparently serve as one of the most important means in vocabulary learning.

9) Students' responses to A37 and A38 clearly indicate that most of them never or rarely used mnemonic devices such as keyword method when they engaged in memorizing vocabulary items.

10) As for the opinions they held for the strategies which they preferred to use when they were involved in memorizing vocabulary items, more than $2 / 3$ of respondents held a positive view of memorizing words by means of semantic strategies and by analysis of word structure.

\subsection{Implications}

Though the scope of the study is rather modest as the questionnaire was administered only to 68 university students, nevertheless, the answers are useful and valuable in analysis of the word learning methods supposed to be used by most of other university students. Their answers to the questions, whether positive or negative, can be regarded as views typical or representative of other Chinese students of English.

The findings of the study indicate that students prefer to engage in the vocabulary learning strategies that would be most appealing to them and that would entail less manipulation of the language. Of the four vocabulary memorizing strategies cited in the study, students apparently tended to favor structural associations and semantic strategies, though rote repetition remains appealing to some of them. Mnemonic devices like keyword method were rather unpopular to most of them because they would involve the learners in more active performance of the target language.

Most of the conventional forms of rote repetition as listed in the questionnaire have been out of the students' favor, 
though some still remain to be frequently used by the students. Those that continue to be appealing to the students are taking notes of vocabulary items in the margins of textbook and word list memorization.

Students at university level get to favor the associational patterns for learning words. Words are stored and remembered in a network of associations. The creation of associations and the continual use of the associations either structurally or semantically enable the learners to retain more words over time. The findings from the students' answers indicate that learning words by associational patterns has gradually replaced most of rote learning forms, which dominated their vocabulary learning when they learned English at middle school. The study shows that many of the traditional forms related to rote repetition have been out of most of the students' favor as their answers show that they held a negative view of many conventional rote learning methods. Learning words in a mechanical fashion not only takes more time but also is easy to forget. The findings suggest that the use of associational patterns for memorizing words is really helpful for learners to retain more words over time.

Keyword mnemonic technique, which has proven effective based on the reports of some researchers, however, is rather unpopular with many language learners. As compared with other word memorizing strategies such as rote repetition, and word associations, keyword mnemonic device has been introduced to China's foreign language education only in recent years, so it is still quite new in language teaching and learning. Students have not got used to this kind of word learning strategy as it would involve them in more active use of the language.

The results of the study have shown that the two most frequently used strategies overall are structural associations and semantic strategies followed by rote repetition. The appearance of a rote strategy among the strategies that students would use when they were involved in word list memorization is of considerable interest in that it indicates that students sometimes were not transforming or otherwise engaging the learning material in an active manner. In general, it seems that some of the more frequently used strategies entail less active manipulation of the learning task, and that active strategies that should lead to greater learning are infrequently used.

\section{References}

Cohen, A. D. (1987). The Use of Verbal and Imagery Mnemonics in Second Language Vocabulary Learning. Studies in Second Language Acquisition. 9: 43-62. http://dx.doi.org/10.1017/S0272263100006501

Cohen, A. D. (1990). Language Learning. Newbury House Publishers.

Cohen, A. D., \& E. Aphek. (1980). Retention of Second Language Vocabulary Over Time: Investigating the Role of Mnemonic Associations. System. 8:221-235. http://dx.doi.org/10.1016/0346-251X(80)90004-4

Cohen, A. D., \& E. Aphek. (1981). Easifying Second Language Learning. Studies in Second Language Acquisition. 3/2: 221-236. http://dx.doi.org/10.1017/S0272263100004198

Nation, I. S. P. (1990). Teaching and Learning Vocabulary. Heinle \& Heinle Publishers.

O’Malley, J. M., \& A. V. Chamot. (1985). Learning Strategies Used By Beginning and Intermediate ESL Adult Students. Language Learning.35/1: 21-46. http://dx.doi.org/10.1111/j.1467-1770.1985.tb01013.x

O’Malley, J. M., \& A. V. Chamot. (1990). Learning Strategies in Second Language Acquisition. Cambridge University Press.

Pickett, G. O. (1978). The Foreign Language Learning Process. The British Council. English Teaching Information Center.

Rivers, W. M. (1983). Communicating Naturally in a Second Language. Cambridge University Press.

Sanaoui, R. (1995). Adult Learners' Approaches to Learning Vocabulary in Second Language. The Modern Language Journal. 79/1:15-28. http://dx.doi.org/10.1111/j.1540-4781.1995.tb05410.x 


\section{Appendix}

[Note: 0 . Never or almost never true of me 1. Rarely or seldom true of me 2. Sometimes true of me 3 . Generally true of me 4. Always or nearly always true of me ]

Note-taking

$$
\begin{array}{llllr}
0 & 1 & 2 & 3 & 4 \\
\% & \% & \% & \% & \%
\end{array}
$$

How I keep notes:

N1. I keep a vocabulary notebook.

$$
\begin{array}{rlllll}
\text { English Majors (E.M.) } & 25 & 31.2 & 25 & 12.5 & 6.2 \\
\text { Non-English Majors (N.E.M.) } & 36.1 & 36.1 & 16.6 & 8.3 & 2.7
\end{array}
$$

N2. I write down a (new) word to remember in separate sections of an English note book.

$\begin{array}{lrccccc} & \text { N.E.M. } & 69.4 & 22.2 & 2.7 & 2.7 & 2.7 \\ \text { N3. I keep my own vocabulary cards } & \text { E.M. } & 90.6 & 3.1 & 3.1 & & 3.1 \\ & \text { N.E.M. } & 77.7 & 16.6 & 2.7 & 2.7 & \\ \text { N4. I keep notes in margins of textbook. } & \text { E.M. } & & 6.2 & 25 & 21.8 & 46.8 \\ & \text { N.E.M. } & 2.7 & 2.7 & 11.1 & 44.4 & 38.8\end{array}$

\begin{tabular}{|c|c|c|c|c|}
\hline E.M & & 6.2 & 6.2 & 21.8 \\
\hline N.E.M & 5.5 & 8.3 & 27.7 & 38.8 \\
\hline
\end{tabular}

How I write down a new item:

N5. I write down a (new) item to remember with Chinese translations.

\begin{tabular}{|c|c|c|}
\hline E.M & & 53.1 \\
\hline N.E.M & 33.3 & 47.2 \\
\hline
\end{tabular}

N6. I write down a (new) item to remember with English synonyms or paraphrase.

N7. I write down a (new) item to remember with its English pronunciation.

$\begin{array}{rlllll}\text { E.M } & 3.1 & 15.6 & 18.7 & 40.6 & 21.8 \\ \text { N.E.M } & 27.7 & 13.8 & 16.6 & 30.5 & 11.1\end{array}$

N8. I write down a (new) item to remember with its grammatical category (e.g. noun, verb, etc.)

$$
\begin{array}{rccccc}
\text { E.M } & & 15.6 & 15.6 & 18.7 & 50 \\
\text { N.E.M } & 19.4 & 36.1 & 36.1 & 8.3 &
\end{array}
$$

N9. I take notes of a (new) item to remember with examples in which it is used.

$\begin{array}{rcrccc}\text { E.M } & 25 & 50 & 12.5 & 6.2 & 6.2 \\ \text { N.E.M } & 11.1 & 27.5 & 44.4 & 13.9 & 2.7\end{array}$

N10. I take notes of a (new) item to remember with its definitions.

$\begin{array}{rccccc}\text { E.M } & 18.7 & 50 & 6.2 & 18.7 & 6.2 \\ \text { N.E.M } & 33.3 & 38.5 & 16.6 & 5.5 & 5.5\end{array}$

How I organize vocabulary notes:

N11. I list items to remember in order as they appear.

$\begin{array}{rlllll}\text { E.M. } & 9.1 & 6.2 & 6.2 & 31.7 & 46.8 \\ \text { N.E.M. } & 16.6 & 5.5 & 8.3 & 36.1 & 33.3\end{array}$

N12. I list items in order as they appear and revise them with additional semantically-related ones.

$\begin{array}{rrrr}\text { E.M. } & 65.6 & 15.6 & 18.7 \\ \text { N.E.M. } & 77.7 & 22.3 & \end{array}$

N13. I list items in an alphabetical order.

$\begin{array}{rlrrrr}\text { E.M. } & 71.8 & 15.6 & 6.2 & 3.1 & 3.1 \\ \text { N.E.M. } & 50 & 11.1 & 27 & 8.3 & 2.7\end{array}$

N14. I list item grammatically (e.g. I group all nouns together, verbs together, etc.)

$\begin{array}{rrrrrr}\text { E.M. } & 71.8 & 12.5 & 6.2 & 9.3 & \\ \text { N.E.M. } & 77.7 & 5.5 & 8.3 & & 8.3\end{array}$




\section{Rote-Learning}

R15. I say the item repeatedly.

$\begin{array}{rllllr}\text { E.M. } & 9.3 & 21.8 & 18.7 & 31.2 & 18.7 \\ \text { N.E.M. } & 11.2 & 13.8 & 22.2 & 44.4 & 8.3\end{array}$

R16. I write the item repeatedly.

$\begin{array}{rrrrrl}\text { E.M. } & 9.3 & 9.3 & 15.6 & 25 & 40.6 \\ \text { N.E.M. } & 2.7 & 11.1 & 22.2 & 38.8 & 25\end{array}$

R17. I read the item repeatedly.

$\begin{array}{rrrrrr}\text { E.M. } & 6.2 & 12.5 & 18.7 & 37.5 & 25 \\ \text { N.E.M. } & 2.7 & 16.6 & 13.8 & 52.7 & 13.8\end{array}$

R18. I listen to the item repeatedly (e.g. listen to the recorder tape of the new vocabulary items.)

$\begin{array}{rlllll}\text { E.M. } & 40.6 & 40.6 & 12.5 & 3.1 & 3.1 \\ \text { N.E.M. } & 50 & 44.4 & 5.5 & & \end{array}$

R19. I say the item with its English synonyms repeatedly.

$\begin{array}{rllll}\text { E.M. } & 40.6 & 28.1 & 18.7 & 12.5 \\ \text { N.E.M. } & 30.5 & 38.8 & 30.5 & \end{array}$

R20. I write the item with its English synonyms repeatedly.

$\begin{array}{rlcccc}\text { E.M. } & 50 & 28.1 & 9.3 & 9.3 & 3.1 \\ \text { N.E.M. } & 30.5 & 36.1 & 19.4 & 13.8 & \end{array}$

R21. I read the item with its English synonyms repeatedly.

$\begin{array}{rrrrrr}\text { E.M. } & 46.8 & 40.6 & 3.1 & 9.3 & \\ \text { N.E.M. } & 30.5 & 36.1 & 25 & 5.5 & 2.7\end{array}$

R22. I say the item with its Chinese translations repeatedly.

$\begin{array}{rrrrll}\text { E.M. } & 59.3 & 6.2 & 9.3 & 15.6 & 9.3 \\ \text { N.E.M. } & 44.4 & 22.2 & 16.6 & 8.3 & 8.3\end{array}$

R23. I write the item with its Chinese translations repeatedly.

$\begin{array}{rrrrr}\text { E.M. } & 65.6 & 18.7 & 3.1 & 12.5 \\ \text { N.E.M. } & 27.7 & 38.8 & 16.6 & 16.6\end{array}$

R24. I read the item with its Chinese translations.

$\begin{array}{rlllll}\text { E.M. } & 53.1 & 12.5 & 15.6 & 12.5 & 6.2 \\ \text { N.E.M. } & 22.2 & 27.7 & 27.7 & 16.6 & 5.5\end{array}$

R25. I review the item and test myself from time to time.

$\begin{array}{rlrrrl}\text { E.M. } & 12.5 & 37.5 & 28.1 & 9.3 & 12.5 \\ \text { N.E.M. } & 2.7 & 33.3 & 38.8 & 16.6 & 8.3\end{array}$

R26. I try to remember items by doing multiple-choice vocabulary exercises sometimes after the lesson.

$\begin{array}{crrrrr}\text { E.M } & 46.8 & 31.2 & 18.7 & & 3.1 \\ \text { N.E.M. } & 30.5 & 41.6 & 16.6 & 11.1 & \end{array}$




\section{Associations}

A27. I associate an English item with another English item according to structure (e.g. root, affix).

$\begin{array}{rrrrrr}\text { E.M. } & & 6.3 & 3.1 & 50 & 40.6 \\ \text { N.E.M. } & 11.1 & & 11.1 & 44.4 & 34.3\end{array}$

A28. I associate a word with other English words by sound only (not meaning) e.g. pair-pare;
piece-peace.
E.M.
$\begin{array}{lllll}6.3 & 25 & 31.2 & 25 & 12.5\end{array}$
N.E.M.
$\begin{array}{lll}19.4 & 30.5 & 38.8\end{array}$
11.1

A29. I associate English words to Chinese words in sound such as humor, jeep, romantic, logic.

$\begin{array}{ccccc}\text { E.M. } & 46.8 & 34.3 & 9.3 & 9.3 \\ \text { N.E.M. } & 72.2 & 22.2 & 2.7 & 2.7\end{array}$

A30. I associate the item with some physical sensation or activity.

$\begin{array}{rlrrrr}\text { E.M. } & 5.5 & 25 & 15.6 & 12.5 & 40.6 \\ \text { N.E.M. } & 16.6 & 13.5 & 13.8 & 30.5 & 25\end{array}$

A31. I associate the item with the situation in which it appeared (e.g. which lesson of the text; who said the item).
E.M.
$\begin{array}{lllll}3.1 & 3.1 & 12.5 & 62.4 & 18.7\end{array}$
N.E.M.
$\begin{array}{lllll}11.1 & 8.3 & 5.4 & 50 & 22.2\end{array}$

A32. I associate the English word with a frequently seen sign (e.g. i---information).

$\begin{array}{rllll}\text { E.M. } & 31.2 & 40.6 & 21.8 & 6.2 \\ \text { N.E.M. } & 47.2 & 44.4 & 8.3 & \end{array}$

A33. I associate the English word with a particular event I have experienced in the past.

$\begin{array}{rrrlll}\text { E.M. } & 25 & 15.6 & 3.1 & 25 & 31.2 \\ \text { N.E.M. } & 25 & 8.3 & 13.8 & 30.5 & 22.2\end{array}$

A34. I try to remember words in meaning group (e.g. garden, vegetables, household articles, etc.).

$\begin{array}{cccccc}\text { E.M. } & 9.3 & 6.2 & 15.6 & 31.2 & 37.5 \\ \text { N.E.M. } & 11.1 & 5.2 & 11.1 & 30.5 & 41.6\end{array}$

A35. I try to remember not only the item but also other words in context.

$\begin{array}{rrrrrl}\text { E.M. } & 37.5 & 25 & 15.6 & 18.7 & 3.1 \\ \text { N.E.M. } & 36.1 & 36.1 & 5.2 & 11.1 & 11.1\end{array}$

A36. I try to remember the item by checking it in a dictionary.

$\begin{array}{rrrrrr}\text { E.M. } & & 3.1 & 25 & 34.4 & 37.5 \\ \text { N.E.M. } & 5.5 & & 25 & 30.5 & 38.8\end{array}$

A37. I make a strong memory connection between the form and meaning of the items.

$\begin{array}{rrrrrr}\text { E.M. } & 18.7 & 50 & 9.3 & 6.2 & 15.6 \\ \text { N.E.M. } & 44.4 & 30.5 & 13.8 & 8.3 & 2.7\end{array}$

A38. I make up pictures in my mind to help remember the item.

$\begin{array}{rlllll}\text { E.M. } & 31.2 & 18.7 & 31.2 & 15.6 & 3.1 \\ \text { N.E.M. } & 44.4 & 36.1 & 19.4 & & \end{array}$




\section{What are your ways of memorizing vocabulary?}

1. Rote Repetition 2. Structure 3. Semantic Strategies 4. Mnemonic Devices 5. No Opinion

1. Which method(s) is (are) do you like?

$\begin{array}{rccccc} & 1 .(\%) & 2 .(\%) & 3 .(\%) & 4 .(\%) & 5 .(\%) \\ \text { E.M } & 25 & 56.2 & 68.7 & 3.1 & 6.2 \\ \text { N.E.M. } & 36.1 & 75 & 80.5 & 11.1 & 11.1\end{array}$

2. Which method(s) is (are) easy?

$\begin{array}{rlllcc}\text { E.M. } & 25 & 40.6 & 31.2 & 12.5 & 3.1 \\ \text { N.E.M. } & 11.1 & 30.5 & 25 & 19.4 & 16.6\end{array}$

3. Which method(s) require(s) you to spend more time?
E.M.
78.1
9.3
12.5

N.E.M.

72.2

8.3

5.5

11.1

4. Which method(s) help(s) you to memorize more vocabulary?

$\begin{array}{rlllll}\text { E.M. } & 28.1 & 68.7 & 56.2 & 3.1 & 6.2 \\ \text { N.E.M. } & 25 & 55.5 & 63.8 & 8.3 & 5.5\end{array}$

5. If you have your choice of method in the future, which method(s) would you use?

$\begin{array}{rrrrrr}\text { E.M. } & 21.8 & 59.3 & 66.6 & 3.1 & 6.2 \\ \text { N.E.M. } & 22.2 & 66.6 & 72.2 & 5.5 & 2.7\end{array}$

\section{Resume}

Yang Weidong, male, born in 1972, lecturer of English with the School of Foreign Languages, China University of Petroleum. Specialize in English Language Teaching. Over 20 papers and books published.

Dai Weiping, male, born in 1956, professor of English with the School of Foreign Languages, China University of Petroleum. Attained M.A. in ELT from Essex University, UK in 1996.Specialize in English Language Teaching . Over 100 papers and books published. 